\title{
“AUTOMATIC MULTISYRINGE FLOW INJECTION SYSTEM FOR THE SPECTROPHOTOMETRIC DETERMINATION OF TINIDAZOLE IN PHARMACEUTICAL PREPARATIONS"
}

\author{
J.L. GUZMÁN-MAR ${ }^{1,2 *}$, L. HINOJOZA-REYES ${ }^{2}$, A. HERNANDEZ-RAMIREZ ${ }^{2}$,J.M. PERALTA-HERNANDEZ \\ V.J. LÓPEZ-CHUKEN ${ }^{2}$, P.L. LÓPEZ-DE-ALBA ${ }^{1}$, V. CERDA-MARTÍN ${ }^{3}$
}

IInstituto de Investigaciones Cientificas, Universidad de Guanajuato, Cerro de la Venada s/n, Guanajuato, Guanajuato, C.P. 36040, Mexico.
\[ \begin{array}{c}\text { Facultad de Ciencias Químicas, Universidad Autónoma de Nuevo León. Pedro de Alba s/n, } \\ \text { Cd. Universitaria. San Nicolás de los Garza, NL, C.P.66400. Mexico. }\end{array} \]
Departamento de Química, Universidad de las Islas Baleares, Carretera de Valldemossa Km. 7.5, Palma de Mallorca, Baleares, E-07122, Spain.

${ }^{3}$ Departamento de Química, Universidad de las Islas Baleares, Carretera de Valldemossa Km. 7.5, Pal
(Received: August 17, 2009 - Accepted: December 7, 2009)

\begin{abstract}
A multisyringe flow injection analysis (MSFIA) method for the determination of tinidazole (TNZ) in pharmaceutical preparations was developed. TNZ concentrations were determined by spectrophotometric detection at $374 \mathrm{~nm}$ wavelength using a light emitting diode (LED). The MSFIA parameters were optimized. Under the optimized experimental conditions, a linear dynamic range from 2 to $56 \mathrm{mg} \mathrm{L}^{-1} \mathrm{TNZ}$, a $3 \sigma$ detection limit of $0.3 \mathrm{mg} \mathrm{L} \mathrm{L}^{-1}$, and a $10 \sigma$ quantification limit of $1.2 \mathrm{mg} \mathrm{L}^{-1}$ were obtained. The relative standard deviation (\%R.S.D.) at 2,28 and $56 \mathrm{mg} \mathrm{L}^{-1}$ was $2.3,1.4$ and $0.9 \%$, respectively ( $\mathrm{n}=10$ ). A sample throughput of 76 determinations $/ \mathrm{h}$ was achieved.
\end{abstract}

Keywords: Multisyringe flow injection analysis (MSFIA); tinidazole (TNZ); alkaline hydrolysis; pharmaceutical formulations.

\section{INTRODUCTION}

Tinidazole (TNZ) is chemically named as (1-(2-ethylsulfonyl-ethyl)-2methyl-5-nitroimidazole (Fig. 1). It is a 5-nitroimidazole derivative used as an antiamoebic, antiprotozoal and antibacterial drug [1]. Owing to its bactericidal and antiprotozoal activity, this chemotherapeutic agent inhibits the growth of both anaerobic bacteria and certain anaerobic protozoa, such as Trichomonas vaginalis, Entamoeba histolytica and Giardia lamblia. It is also an important constituent of modern multidrug therapies for Helicobacter pylori eradication regimes used to control ulcers $[1,2]$. TNZ has been found to be equally or more effective than metronidazole (MTZ) in the treatment of trichomoniasis, giardiasis, and amebiasis [3]. Additionally, TNZ has shown a greater tolerability, a longer half-life, and a more favorable side-effect profile than MTZ $[3,4]$; therefore, analytical methods for its quantification are required for quality control purpose.

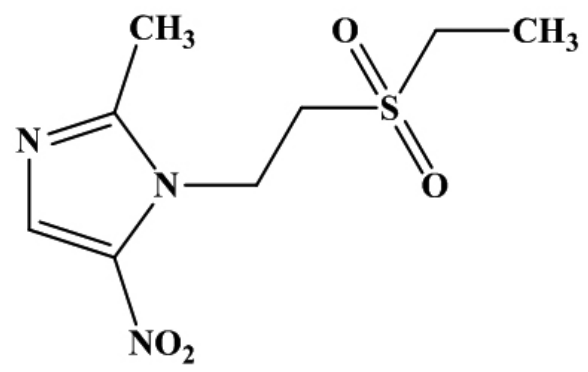
(TNZ).

Fig. 1. Structure of 1-[2-ethylsulphonil)ethyl]-2-methyl-5-nitroimidazole

TNZ shows an absorption spectrum peak maximum in an aqueous solution at $313 \mathrm{~nm}$ and hydrolyzes in alkaline conditions to 2-methyl-4(5)nitroimidazole, with an absorption spectrum peak maximum at $374 \mathrm{~nm}$ (Fig. 2). This reaction has been studied and the hydrolysis products obtained have been identified and reported elsewhere [5-8].

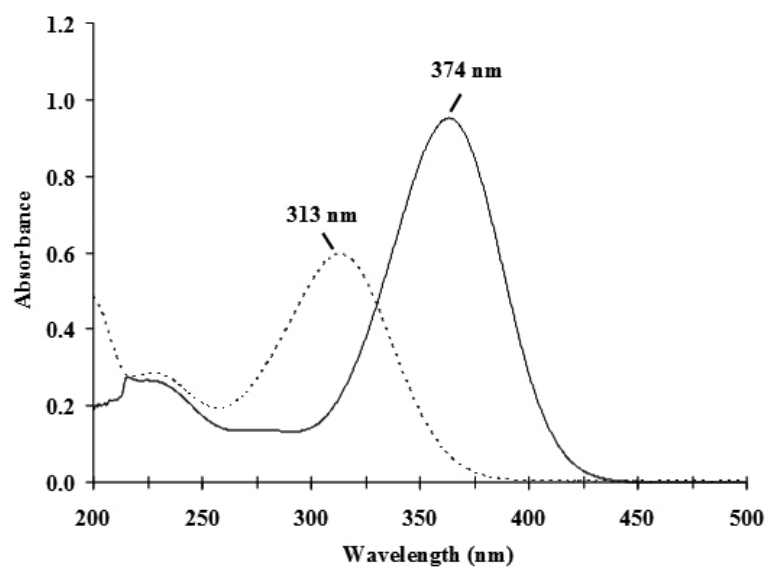

Fig. 2. Absorption spectra of TNZ (40 $\left.\mathrm{mg} \mathrm{L}^{-1}\right)$ before (---) and after (-) alkaline hydrolysis.

Several analytical methods for the determination of TNZ in pharmaceutical preparations, feedstuff or human plasma have been developed, including high performance liquid chromatography (HPLC) [9,10], capillary electrophoresis (CE) [11,12], liquid chromatography-mass spectrometry (LC-MS) [13], voltammetry [14], electrochemical methods [15], resonance light scattering (RLS) [16] and spectrophotometry $[5,17,18]$.

Multisyringe flow injection analysis (MSFIA) is a fluid approach recently developed [19]. MSFIA includes advantages of both sequential injection and flow injection methodologies, such as robustness, flexibility, low reagent consumption and simultaneous flow of solutions, which enables the mixing of sample and reagents in proper confluence points. Since the liquids are only in contact with the glass syringes or PTFE tubing from the manifold, both aggressive reagents and organic solvents may be used in MSFIA without requiring the periodic calibration of the analyzer. Furthermore, the great variety of available syringes $(0.5,1,2.5,5,10$ and $25 \mathrm{~mL}$ of capacity) provides to the method a high flexibility $[20,21]$.

The aim of this work was to develop a robust, rapid and simple MSFIA procedure for the determination of TNZ using spectrophotometric detection, taking benefit from the selectivity of the above mentioned reaction in which TNZ was hydrolyzed in alkaline medium. The interfacing of the flow setup with a miniaturized fiber optical-based diode-array spectrophotometer equipped with a light emitting diode (LED) radiation at $374 \mathrm{~nm}$ was used. 


\section{EXPERIMENTAL}

\subsection{Reagents and solutions}

Analytical grade reagents and double-deionized water (DDI water, resistivity $>18 \mathrm{M} \Omega \mathrm{cm}$ ) from Milli-Q system (Millipore, Bedford, MA, USA) was used to prepare all the solutions. A stock solution of $1000 \mathrm{mg} \mathrm{L}^{-1}$ TNZ in DDI water (Sigma Aldrich Chemical Co., St. Louis, MO, USA) was prepared, from which the remaining working standard solutions required for the calibration curve were obtained. $\mathrm{NaOH}$ (Merck, Darmstadt, Germany) was used to prepare several solutions at different molarities.

\subsection{Instrumentation}

The multisyringe flow injection analysis (MSFIA) manifold employed for TNZ determination by alkaline hydrolysis reaction is depicted in Fig. 3. The system basically consisted of a multisyringe module (Model: BU-4-S, Crison, Alella, Barcelona, Spain) with four syringes (S) (Hamilton, Switzerland) which had a three-way commutation valve (V) (N-Research Inc., 3-way isolation standard, Caldwell, NJ, USA) connected to each of them. Another independent commutation was connected to the back of the module.

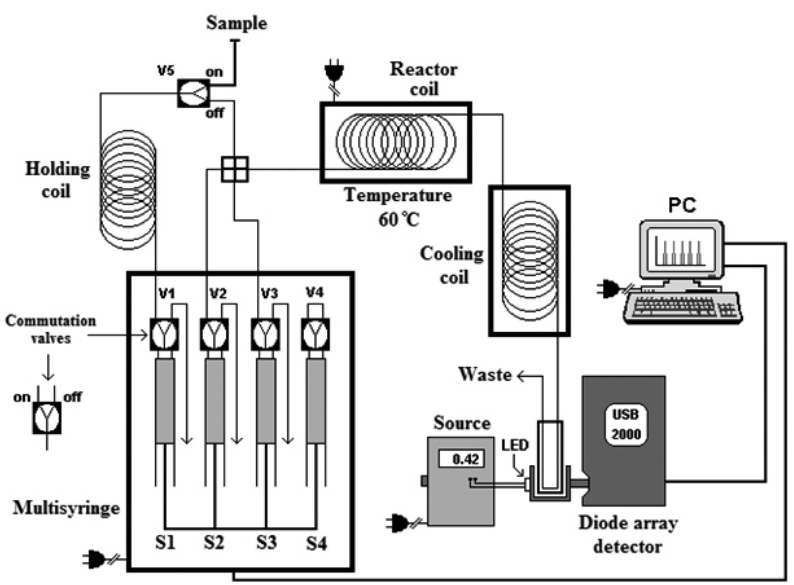

Fig. 3. MSFIA setup proposed for the determination of TNZ.

The miniaturized optical detector involved an diode array USB 2000 spectrophotometer (Ocean Optics, Dunedin, FL, USA) connected to a PC through a USB port and a quartz flow-through cell $(10 \mathrm{~mm}$ optical path and $36 \mu \mathrm{L}$ inner volume) via a single optical fiber (P400-2-UV-VIS, Ocean Optics, Dunedin, FL, USA) with a core diameter of $400 \mu \mathrm{m}$. The analytical wavelength was set at $374 \mathrm{~nm}$. A light emitting diode (LED, maximum intensity of $15 \mathrm{~mA}$, Sciware, Palma de Mallorca, Spain) with a power supply of adjustable intensity was used as a light source.

The manifold was built with 0.8 and $1.5 \mathrm{~mm}$ i.d. polytetrafluoroethylene (PTFE, Teflon). The holding coil, reactor coil and cooling coil were 200, 600 and $200 \mathrm{~cm}$ long, respectively. A Teflon reactor coil immersed in a water bath with temperature control (Fanem LTDA, Mod. 102/1, Ind. Brasileira) was employed to carry out the hydrolysis reaction on-line. For instrumental control, data acquisition and processing, AutoAnalysis v.5.0 software (Sciware, Palma de Mallorca, Spain) was used.

\subsection{MSFIA procedure for TNZ monitoring}

The MSFIA system proposed (see Fig. 3) involved the use of four syringes (S1, S2, S3 and S4) with their corresponding three-way commutation valves (V1, V2, V3 and V4), in addition to an external commutation valve (V5). The head valves of the syringes in the "off" position were connected to the right channel and in the "on" position to the left channel. The V5 valve allowed the loading of the sample in the "on" position and dispensing of a certain volume in the "off" position. S1 (connected to the commutation valve V1) was responsible for loading and dispensing the sample in combination with valve V5, as well as for cleaning the manifold. Syringes S2 and S3, with their commutation valves $\mathrm{V} 2$ and $\mathrm{V} 3$, contained, respectively, $\mathrm{NaOH}$ to accomplish the hydrolysis reaction, and the carrier (DDI water). Syringe $\mathrm{S} 4$ and its commutation valve V4 were not in use. The four syringes had a capacity of $5 \mathrm{~mL}$.

The alkaline hydrolysis reaction of TNZ produced a bathocromic shift from 313 to $374 \mathrm{~nm}$, along with a hyperchromic effect, which implies higher sensitivity and selectivity in terms of determination. An absorbance increase of over $40 \%$ for the same concentration after the alkaline hydrolysis reaction was observed. The reagent responsible for the hydrolysis was found in syringe $\mathrm{S} 2$ and was released into the same flow as sample S1 towards the reactor coil. The reaction temperature, an important factor to take into account, was studied and will be examined in detail in the result and discussion section. With carrier S3, the hydrolyzed product was dispensed from the reactor coil and subsequently injected into the flow-through cell where detection took place, prior to acclimatization of the hydrolysis product in a cooling coil.

\subsection{Procedure for the assay of TNZ in commercial samples.}

Ten tablets were ground until a fine powder was obtained and a representative amount was accurately weighed, then carefully stirred in DDI water for $30 \mathrm{~min}$, filtered, and diluted to a known volume with DDI water. Suitable aliquots of the solution were used to carry out the analysis according to the above MSFIA procedure.

\section{RESULTS AND DISCUSSION}

As mentioned above, TNZ was susceptible to hydrolyze in alkaline medium, generating a new species, which presented high stability, sensitivity and selectivity, with an absorption spectrum peak maximum in aqueous solution at $374 \mathrm{~nm}$ (see Fig. 2). Hydrolysis reaction parameters and MSFIA were thoroughly examined and optimized.

\subsection{Optimization of the hydrolysis reaction parameters.}

The influence of relevant reaction parameters such as $\mathrm{NaOH}$ concentration, reaction temperature and time were studied. In Fig. 4a, the effect of $\mathrm{NaOH}$ concentration from 0.2 to $3 \mathrm{M}$ is shown, and a clear tendency towards an increase in the absorbance signal up to $2 \mathrm{M}$, remaining practically constant up to $3 \mathrm{M}$, was observed.
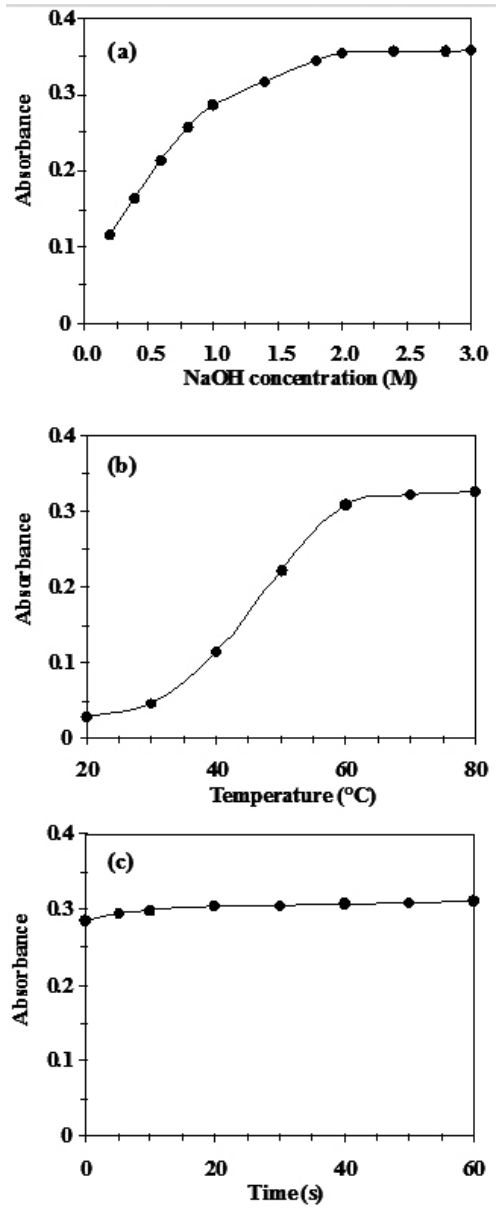

Fig. 4. Effect of $\mathrm{NaOH}$ concentration, temperature and time on the hydrolysis reaction of TNZ (24 mg L-1 of TNZ was injected). 
Reaction temperature was observed to be an important factor, acting to accelerate the hydrolysis reaction. When the hydrolysis reaction was carried out at room temperature, the reaction took approximately $30 \mathrm{~min}$; however, it proceeded more rapidly upon increasing temperature. The results in Fig. 4b, encompassing a temperature range from 20 to $80^{\circ} \mathrm{C}$, revealed that absorption increased with temperature, and this effect was especially notable from $40{ }^{\circ} \mathrm{C}$ onwards, with the increase noted until reaching $80{ }^{\circ} \mathrm{C}$. Nevertheless, in the range from 60 to $80^{\circ} \mathrm{C}$ the increase became less significant; thus, a thermostatic bath at $60{ }^{\circ} \mathrm{C}$ over the reactor coil was employed in order to ensure faster conversion in the hydrolysis reaction of TNZ.

Once the reaction temperature was set at $60^{\circ} \mathrm{C}$ and a concentration of $2 \mathrm{M}$ $\mathrm{NaOH}$ was established, the time required to obtain the maximum conversion was considerably reduced, in relation to the reaction time at room temperature. Therefore, the study of reaction time was shown to be valuable since shorter reaction times involved a higher sampling frequency or a greater number of possible analyses. This experiment is shown in Fig. 4c, in the working range from 0 to $60 \mathrm{~s}$, with the maximum signal remaining constant within the entire range studied. A reaction time of $10 \mathrm{~s}$ was proposed, with which a very fast conversion time in the hydrolysis reaction was ensured. Herein, as opposed to the conventional spectrophotometric method [17], the $\mathrm{NaOH}$ volume used for hydrolysis was drastically reduced from $5 \mathrm{~mL}$ to $0.2 \mathrm{~mL}$, the reaction time was decreased from $600 \mathrm{~s}$ to $10 \mathrm{~s}$, and the reaction temperature was reduced from 100 to $60^{\circ} \mathrm{C}$.

\subsection{Optimization of MSFIA parameters}

The influence of sample and $\mathrm{NaOH}$ volumes was studied; in both cases, volume was varied from 0.1 to $1.0 \mathrm{~mL}$. Results are shown in Fig. 5. Results for the sample volume experiment indicated an increase in the signal intensity with volumes between 0.1 to $0.4 \mathrm{~mL}$; from 0.4 to $1.0 \mathrm{~mL}$ a practically constant signal was observed. With regard to $\mathrm{NaOH}$ volume, absorbance intensity at 374 $\mathrm{nm}$ remained practically constant throughout the entire volume range. Based on these results, a sample volume of $0.4 \mathrm{~mL}$ and a $\mathrm{NaOH}$ volume of $0.2 \mathrm{~mL}$ were proposed.

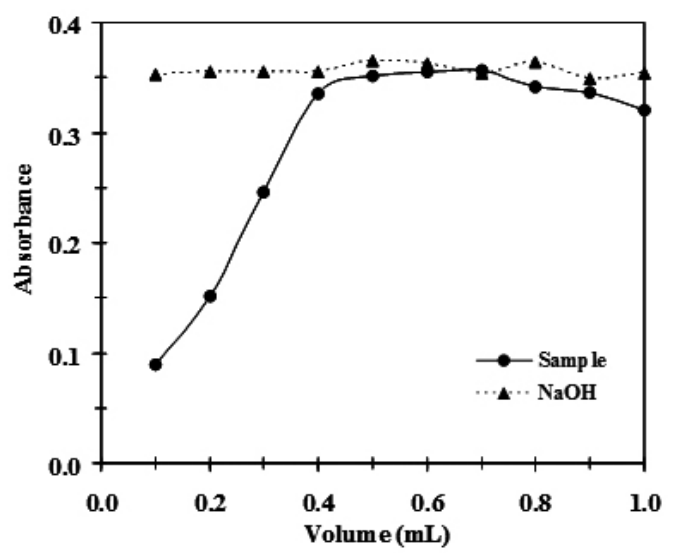

Fig. 5. Study of sample and $\mathrm{NaOH}$ volumes in the hydrolysis reaction of TNZ. Reported absorbance for $24 \mathrm{mg} \mathrm{L}^{-1}$ of TNZ and $2 \mathrm{M} \mathrm{NaOH}$.

An experiment was performed to determine the optimal length of the reactor coil, with possibilities being $200,300,400$ and $600 \mathrm{~cm}$ (i.d. $=0.8 \mathrm{~mm}$ ), and the optimal length of the cooling coil, with evaluated lengths of 100, 200, 300,400 and $600 \mathrm{~cm}$ (i.d. $=0.8 \mathrm{~mm}$ ). Results demonstrated that in both cases there was a reduction in the signal intensity when the coil length was increased; however, the gradual reduction in absorbance intensity was compensated by greater measuring precision. The error percentages $(\% \mathrm{E})$ were calculated for the evaluated coil lengths; results were: $2.5,2.2,0.7$ and $0.6 \% \mathrm{E}$ for the respective reactor coil lengths, and 1.9, 0.9, 2.1, 3.4 and $4.0 \% \mathrm{E}$ for the respective cooling coil lengths. For all cases, $n=10$. A reactor coil length of $600 \mathrm{~cm}$ and a cooling coil length of $200 \mathrm{~cm}$ was proposed, since this was the combination that provided the highest precision in determination of TNZ.

The influence of the injection flow of sample, $\mathrm{NaOH}$, and carrier was investigated within the range $4-15 \mathrm{~mL} \mathrm{~min}^{-1}$. Injection flow rate did not affect TNZ determination. Injection flow rates of $12 \mathrm{~mL} \mathrm{~min}^{-1}$ for the sample and $\mathrm{NaOH}$, and $13 \mathrm{~mL} \mathrm{~min}^{-1}$ for the carrier flow were selected. It should be noted that the consumption was $0.4 \mathrm{~mL}$ for the sample and $0.2 \mathrm{~mL}$ for $\mathrm{NaOH}$ in each injection. Under the optimal conditions, a sample throughput of 76 injections per hour was attained. The selected MSFIA variables for the determination of TNZ are listed in Table 1.

Table 1. Optimized MSFIA parameters.

\begin{tabular}{|c|c|}
\hline \multicolumn{2}{|c|}{ Reaction parameters } \\
\hline $\mathrm{NaOH}$ concentration & $2 \mathrm{M}$ \\
\hline Reaction temperature & $60^{\circ} \mathrm{C}$ \\
\hline Reaction time & $10 \mathrm{~s}$ \\
\hline \multicolumn{2}{|c|}{ MSFIA parameters } \\
\hline Sample consumption per injection & $0.4 \mathrm{~mL}$ \\
\hline $\mathrm{NaOH}$ consumption per injection & $0.2 \mathrm{~mL}$ \\
\hline Carrier consumption per injection & $5 \mathrm{~mL}$ \\
\hline Holding coil & $200 \mathrm{~cm}$ \\
\hline Reactor coil & $600 \mathrm{~cm}$ \\
\hline Cooling coil & $200 \mathrm{~cm}$ \\
\hline Syringe (S1) V1 (5 mL) & Sample \\
\hline Syringe (S2) V2 (5 mL) & $\mathrm{NaOH}$ \\
\hline Syringe (S3) V3 (5 mL) & Carrier $\left(\mathrm{H}_{2} \mathrm{O}\right)$ \\
\hline Sample flow rate & $12 \mathrm{~mL} \mathrm{~min}^{-1}$ \\
\hline $\mathrm{NaOH}$ flow rate & $12 \mathrm{~mL} \mathrm{~min}^{-1}$ \\
\hline Reactor coil flow rate & $12 \mathrm{~mL} \mathrm{~min}^{-1}$ \\
\hline Cooling coil flow rate & $12 \mathrm{~mL} \mathrm{~min}^{-1}$ \\
\hline Carrier flow rate & $13 \mathrm{~mL} \mathrm{~min}^{-1}$ \\
\hline Sample throughput & 76 injections $\mathrm{h}^{-1}$ \\
\hline
\end{tabular}

\subsection{Analytical parameters}

A calibration graph was obtained for TNZ treated according to the procedure described above. The MSfiagram obtained with its corresponding calibration graph using a sample volume of $400 \mu \mathrm{L}$ is shown in Fig. 6. The quadruplicate signals demonstrated good reproducibility. A dynamic linear working range for TNZ concentrations in the range from 2 to $56 \mathrm{mg} \mathrm{L}^{-1}$ was obtained, with an estimated detection limit (LOD) and quantification limit (LOQ) of 0.3 and $1.2 \mathrm{mg} \mathrm{L}^{-1}$, respectively. Equation for calibration graph was obtained by least-square linear regression analysis of the height of analyte standard spectrophotometric signals versus analyte concentrations: $\mathrm{A}=$ $0.0112 \pm 0.0001$ [TNZ] $-0.0031 \pm 0.0014$. Where $\mathrm{A}$ is the relative absorbance intensity and [TNZ] is the concentration of TNZ. The correlation coefficient was 0.9997 . The relative standard deviations (\% R.S.D.) and relative error percentages (\% E) were calculated for three concentration levels: 2, 28 and $56 \mathrm{mg} \mathrm{L}^{-1}$; values obtained were $2.3,1.4$ and $0.9 \%$ R.S.D., and 1.7, 0.9 and $0.7 \% \mathrm{E}$, respectively. The analytical characteristics in terms of dynamic linear range and detection limits were comparable to that achieved in capillary electrophoresis with UV detection [12], HPLC with UV detection [13] and spectrophotometric methods $[5,17,18]$. 


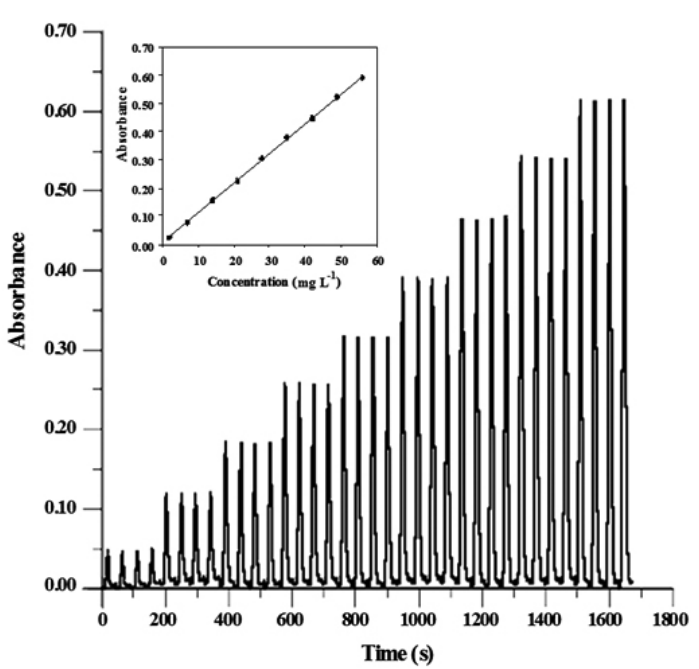

Fig. 6. MSfiagram for calibration curve in the concentration range from 2 to $56 \mathrm{mg} \mathrm{L}^{-1}$ ( $400 \mu \mathrm{L}$ sample volume).

\subsection{Applications to real samples}

The results obtained in the determination of TNZ in pharmaceutical formulations by the proposed and reference methods are summarized in Table 2. For both cases, concentrations of TNZ were calculated using the external calibration and the standard addition method, and results for both calculation techniques are compared in Table 2. For the proposed method, the results for TNZ concentrations in pharmaceutical formulations using these two quantification methods were statically indistinguishable at the $95 \%$ confidence level. These results indicated that common excipients that often accompanied the pharmaceutical formulations such as sucrose, glucose, talc, fructose, lactose, microcrystalline cellulose, starch, and/or magnesium stearate did not interfere in the determination of TNZ. The results of the MSFIA assay on the pharmaceutical preparations were cross cheeked by the reference method [17]. The results obtained by the reference method were systematically lower and the precision was inferior compared with the proposed methodology. The reason for this difference could be related to the fact that the alkaline hydrolysis procedure used in the spectrophotometric method was carried out in beaker heated in a thermostat water bath at $100{ }^{\circ} \mathrm{C}$, thereby allowing the loss of the analyte.

Table 2. Results obtained in the determination of TNZ in pharmaceutical preparations.

\begin{tabular}{|c|c|c|c|c|c|}
\hline \multirow{2}{*}{$\begin{array}{c}\text { Commercial } \\
\text { formulation }\end{array}$} & \multirow{2}{*}{$\begin{array}{c}\text { Label } \\
\text { claim } \\
(\boldsymbol{m g})\end{array}$} & \multicolumn{2}{|c|}{ Proposed method } & \multicolumn{2}{|c|}{ Reference method $[17]$} \\
\cline { 3 - 6 } & & $\begin{array}{c}\text { External } \\
\text { calibration }\end{array}$ & $\begin{array}{c}\text { Standard } \\
\text { addition }\end{array}$ & $\begin{array}{c}\text { External } \\
\text { calibration }\end{array}$ & $\begin{array}{c}\text { Standard } \\
\text { addition }\end{array}$ \\
\hline $\begin{array}{c}\text { Tricolam } \\
\text { (Farmasierra } \\
\text { S.A., Spain) }\end{array}$ & 500 & $490.7 \pm 0.3$ & $493.5 \pm 0.1$ & $492.3 \pm 0.9$ & $496.2 \pm 1.5$ \\
\hline $\begin{array}{c}\text { Fasigyn } \\
\text { (Pfizer S.A., } \\
\text { Mexico) }\end{array}$ & 500 & $503.1 \pm 0.3$ & $502.3 \pm 0.2$ & $495.2 \pm 0.8$ & $496.8 \pm 1.9$ \\
\hline $\begin{array}{c}\text { Estovyn*t } \\
\text { (ICN }\end{array}$ & & $505.5 \pm 0.2$ & $503.2 \pm 0.1$ & $496.1 \pm 0.7$ & $497.9 \pm 1.6$ \\
$\begin{array}{c}\text { Farmacéutica } \\
\text { S.A., } \\
\text { Mexico) }\end{array}$ & 500 & $502.3 \pm 0.2$ & $503.4 \pm 0.2$ & $498.3 \pm 0.8$ & $499.2 \pm 1.5$ \\
\hline $\begin{array}{c}\text { Trinigyn } \\
\text { (Grünenthal S.A., } \\
\text { Mexico) }\end{array}$ & 500 & & & \\
\hline
\end{tabular}

${ }^{a}$ Average of ten determinations $\pm 95 \%$ confidence level.

\section{CONCLUSION}

A simple and rapid MSFIA method was developed for the determination of TNZ with UV spectrophotometric detection using a LED as the source light centered at $374 \mathrm{~nm}$. The main advantages of the MSFIA approach proposed in this study were, undoubtedly, the rapid determination of TNZ in pharmaceutical formulations, the ease of sample preparation, and the low cost of reagents and instruments used. Compared with a previous published spectrophotometric method [17], the proposed assay was applied with satisfactory precision and accuracy to the determination of TNZ in tablets. The method is time-efficient; a single analysis takes about $10 \mathrm{~s}$. The precision and simplicity attained by the proposed system resulted in a higher sample throughput (76 injections per hour) and lower reagent consumption without losses of the analyte. The proposed method was found to be a worthy alternative for quality control purposes in the pharmaceutical industry.

\section{ACKNOWLEDGEMENTS}

This work was supported by the National Council of Science of Technology of Mexico (CONACyT), SEP-PROMEP 103.5/09/3905 and UANL-PAICYT 2009.

\section{REFERENCES}

1.- W. Raether, and H. Hanel, Parasitol. Res., 90, S19 (2003).

2.- J.S.Williamson, Curr. Pharm. Des., 7, 355 (2001).

3.- H.B. Fung, and T.L. Doan, Clin. Ther., 27, 1859 (2005).

4.- M.M.L. Nigro, and M.A. Carballo, Toxico. Lett., 180, 46 (2008).

5.- P. Nagaraja, K.R. Sunitha, R.A. Vasantha, and H.S. Yathirajan. J. Pharm. Biomed. Anal., 28, 527 (2002).

6.- J.P. Salo, and H. Salomies. J. Pharm. Biomed. Anal., 14, 1261 (1996).

7.- J.P.K. Salo, and H.Salomies . J. Pharm. Biomed. Anal., 31, 523 (2003).

8.- H. Salomies, Acta Pharm. Nord., 3, 11 (1991).

9.- D. Habel, S. Guermouche, and M.H. Guermouche, Biomed. Chromatogr., 11, 16 (1997).

10.- H.W. Sun, F.C. Wang, and L.F. Ai. J. Chromatogr. B., 857, 296 (2007).

11.- A. Alnajjar, H.H. AbuSeada, and A.M. Idris, Talanta, 72, 842 (2007).

12.- L.Y. Zhang, Z.J. Zhang, and K. Wu, J. Pharm. Biomed. Anal., 41, 1453 (2006).

13.- L.F. Capitan-Vallvey, A. Ariza, R. Checa, and N. Navas, Chromatographia, 65,283 (2007).

14.- C.H. Wang, F. Wang, C.Y. Li, X.L. Xu, T. Li, and C.F. Wang, J. Pharm. Biomed. Anal., 41, 1396 (2006).

15.- A.Z. Abu Zuhri, S. Al-Khalil, R.M. Shubietah, and I.El-Hroub, J. Pharm. Biomed. Anal. 21, 881 (1999).

16.- X-Y Jiang, X.Q. Chen, Z. Dong, and M. Xu, J. Autom. Meth. Manag. Chem. 1 (2007).

17.- L. Lopez Martinez, F.J.L. Vazquez, and P.L. Lopez de Alba, Anal. Chim. Acta. 340, 241 (1997).

18.- C.V.N. Prasad, V. Sripriya, R.N. Saha, and P. Parimoo, J. Pharm. Biomed. Anal. 21, 961 (1999).

19.- V. Cerdá, J. M.Estela, R. Forteza, A. Cladera, E. Becerra, P. Altimira, and P. Sitjar, Talanta 50, 695 (1999).

20.- V. Cerdà, J. Flow Injection Anal., 20, 203 (2003).

21.- M.A. Segundo, and L.M. Magalhaes, Anal. Sci., 22, 3 (2006). 